\title{
Influence of Oxidation Media on the Transport Properties of Thin Oxide Layers of Zirconium Alloys
}

\section{H. Frank}

Two batches of tubes of $\mathrm{Zr} 1 \mathrm{Nb}$ and of $\mathrm{Zry}-4 \mathrm{~W}$ were oxidized for 30 days at $425^{\circ} \mathrm{C}$ in steam, and for 360 days at $500^{\circ} \mathrm{C}$ in air, respectively. The analysis of the I-V characteristics at constant temperatures up to $220^{\circ} \mathrm{C}$ of oxide layers of nearly equal thickness gave an activation energy of 1,3 eV for the grey homogeneous steam samples, and of $0.4 \mathrm{eV}$ for the white surface layer, and of $1.3 \mathrm{eV}$ at temperatures over $140^{\circ} \mathrm{C}$, for the grey bottom layer of the air samples, respectively. The I-V characteristics were sub-linear in the air samples, the current growing less at rising voltages, but staightening to super-linear space-charge limited currents at higher temperatures. The injection currents flowing when voltage was applied did not reach constant equilibrium, but at a bend, continued with a lesser slope. The resistivity was about one order of magnitude greater in air samples and greater in Zry-4W. The relative permittivity was greater in the steam samples and greater in $\mathrm{Zr} 1 \mathrm{Nb}$. The currents of the air samples were greater with Au electrodes than with Ag electrodes.

Keywords: Zirconium alloys, oxide layers, relative permittivity, sub-linear I-V characteristics, space-charge limited current, zero-voltage, injection and extraction current, power law of current drop, temperature dependence of resistivity, activation energy.

\section{Introduction}

The results presented in this paper were achieved continuing the investigation of the transport properties of oxide layers of zirconium alloys described earlier [1,2].

Unlike to previous samples oxidized in water at VVVR conditions, the oxidation was performed in steam at $425^{\circ} \mathrm{C}$, and in air at $500{ }^{\circ} \mathrm{C}$, respectively, to assess possible differences in transport properties due to the influence of hydrogen originating from dissociation of the water molecules in steam. Zirconium alloys are used as fuel cladding and channel box materials in nuclear light water reactors because of their enhanced corrosion resistance [3, 4].

The corrosion rate depends largely on electron motion, which is governed by the electrical conductivity of the oxide layer. It is therefore of interest to investigate the electrical transport properties of the oxide layers with regard to oxide-forming capability and an assessment of corrosion resistance.

The excellent corrosion resistance of the alloys in an aqueous solution is attributed to the formation of a passive film on the surface. Lee et al. [5] investigated the passive film on Zircaloy-4 by a photo-electrochemical method. The oxide consisted of an inner anhydrous layer with a band gap of $4.30 \mathrm{eV}$, and an outer hydrous $\mathrm{ZrO}_{2}$ layer with a band gap of $2.98 \mathrm{eV}$. Cox [6] found that electronic conductivity is controlled by small amounts of alloying elements. Howlader et al. [7] concluded that electron conduction dominates the electrical conductivity of Zircaloy oxide films. They measured the conductivity and $I-V$ characteristics over a wide temperature range using various electrode metals.

The oxide layer was not uniform. There was black hypostoichiometric layer of relatively high conductivity near the oxide-metal interface, whereas the outer layer was white and of high resistivity, as was shown metallographically by Cox et al. [14]. It is well known [7-9] that bulk $\mathrm{ZrO}_{2}$ is predominantly an electronic high-resistivity semiconductor with a certain amount of ionic conduction at higher temperatures [7]. The band gap is approximately $5 \mathrm{eV}$, work function $4.0 \mathrm{eV}$, and relative permittivity 22 . The observed activation energy is determined by the distance between the trap levels and the lower edge of the conduction band [10].

\section{Samples}

Two tube specimens $30 \mathrm{~mm}$ long and of $9 \mathrm{~mm}$ outer diameter prepared from the zirconium alloys $\mathrm{Zr} 1 \mathrm{Nb}$ and $\mathrm{Zry}-4 \mathrm{~W}$ were oxidized in steam of $10.7 \mathrm{MPa}$ at $425^{\circ} \mathrm{C}$ in an autoclave of 701 volume (according to ASTM G2M-88) for 360 days, and two other specimens of the same alloys were oxidized in air at $500{ }^{\circ} \mathrm{C}$ for 31 days. Due to the dissimilar growth rate,

Table 1: Chemical composition (wt \%) of the Zircaloys used in this study

\begin{tabular}{|c|c|c|c|c|}
\hline & $\mathrm{Nb}$ & $\mathrm{Sn}$ & $\mathrm{Fe}$ & $\mathrm{Cr}$ \\
\hline $\mathrm{Zr} 1 \mathrm{Nb}$ & 1 & & & \\
\hline Zry-4W & & 1.3 & 0.2 & 0.1 \\
\hline
\end{tabular}

Table 2: Characterization of the samples

\begin{tabular}{|l|l|c|c|c|c|c|}
\hline Sample & short name/medium & $\mathrm{T}\left({ }^{\circ} \mathrm{C}\right)$ & time $(\mathrm{d})$ & thickness $(\mu \mathrm{m})$ & $\varepsilon_{r}$ & colour \\
\hline Zr1Nb 1744323 & Zr1Nb steam & 425 & 360 & 33.3 & 20.5 & light grey \\
Zr1Nb NM034 & Zr1Nb air & 500 & 31 & 29.8 & 15.0 & white \\
\hline Zry-4W 3744323 & Zry-4W steam & 425 & 360 & 35.3 & 17.2 & dark grey \\
Zry-4W 3890085 & Zry-4W air & 500 & 31 & 32.4 & 11.4 & light brown \\
\hline
\end{tabular}


different oxidation times were chosen in order to achieve oxide layers of approximately the same thickness of about $30 \mu \mathrm{m}$. The chemical composition of the samples is given in Table 1, and the sample parameters are shown in Table 2.

The samples were wrapped in Al-foil with circular openings of $6.0 \mathrm{~mm}$ diameter and gold of $300 \mathrm{~nm}$ thickness on a substrate layer of $30 \mathrm{~nm}$ Ti was vacuum evaporated. Close by a contact of colloidal silver (Degussa) was painted on for the purpose of comparison.

\section{Experimental}

The samples were mounted in a small thermostat with a maximum temperature of $220^{\circ} \mathrm{C}$. The abraded front ends of the tubes of shining zirconium metal were in direct contact with pressed-on copper electrodes, on which a thermocouple was mounted for temperature control. The current was measured with a two-electrode arrangement, using only one contact for each electrode. The contact resistance between the pressed-on copper electrodes and the metallic bulk zirconium is certainly negligible in comparison with the layer resistance of more than $G \Omega$, the same being true for the resistance between the metallic surface electrode and the pressed-on $0.3 \mathrm{~mm}$ thick phosphorbronze contact spring, $50 \mathrm{~mm}$ in length, to minimize thermal loading. A stabilized voltage source was connected to the $\mathrm{Zr}$ metal. The surface electrode was earthed via a picoampere-meter with $0.1 \mathrm{pA}$ resolution. The voltage drop of the meter was limited to $10 \mathrm{mV}$ and was negligible at source voltages over $1 \mathrm{~V}$. The $I-V$ characteristics were measured at room temperature and at constant higher temperatures up to $220{ }^{\circ} \mathrm{C}$, mostly in steps of about $20^{\circ} \mathrm{C}$. The normally existing asymmetry of the complete $I-V$ characteristics due to a certain rectifying effect was not observed in this case. Therefore only the forward voltage branch, with the positive voltage source terminal connected to the zirconium metal, was measured. Current measurements $I=f(T)_{U}$ with a low constant voltage in the ohmic range at continually rising temperature with a rate of $1{ }^{\circ} \mathrm{C} / \mathrm{min}$ were used to determine the activation energy by means of the slope of $\log \rho=f(1 / T)$, the temperature dependence of the resistivity.

After being painted on, the silver contact was left to dry in air at room temperature for several hours, and was then slowly heated in the thermostat. The short-circuit current was measured without applying an external voltage. After the first heating, which served to anneal the silver contact, the same procedure was repeated after cooling down to room temperature, and the values of the short-circuit current and open circuit voltage were used to plot the temperature dependence of the resistivity and to compute the activation energy. The observed short-circuit current is ionic and is due to the continuing oxidation of zirconium in air at elevated temperatures [1]. Then the capacity was measured with a TESLA BM 498 type capacitance bridge operating at $1000 \mathrm{~Hz}$ with $0.1 \%$ precision.

The $I-V$ characteristics of homogeneous high resistivity semiconductors start at low voltages with a linear part obeying Ohm's law. When higher voltages are applied the current rises faster due to the injection of majority carriers building up a space charge. The current develops a space-charge limited additional part. The measured current values can be fitted to a second order polynomial

$$
I=a U^{2}+b U+c .
$$

The zero-current expressed by constant c can be observed at elevated temperatures as a consequence of temperature-activated liberation of trapped electrons and/or continuing oxidation in air. Constant $b$ is the slope of the linear part of the chacteristic and can be used to compute the resistivity

$$
\rho=\frac{a}{w b},
$$

where $A$ is the area of the contact and $w$ is the thickness of the layer. The first term of Eq.(1) is the space-charge limited current and obeys Child's law [11]

$$
I_{s c}=\frac{9}{8} \varepsilon \varepsilon_{0} A \mu \frac{U^{2}}{w^{3}}=a U^{2},
$$

where $\varepsilon \varepsilon_{0}$ is the relative and vacuum permittivity, respectively, $\mu$ is the mobility of the carriers and $U$ the applied voltage. The transition of the current from the linear to the square part occurs at the voltage $U=b / a$. Further details concerning theoretical aspects are given in [13].

\section{Results and discussion}

\subsection{Influence of media on oxide growth rate}

Table 2 shows the astonishing fact that the time to obtain equal thicknesses of the oxide layers is about ten times longer, if the sample is oxidized in steam instead of in air. It is possible that in steam, an aqueous environment, the formation of a passive film on the surface as proposed by Lee et al. [5] is responsible for the enhanced corrosion resistance. It may also be possible to assume that the diffusing oxygen, which is responsible for the oxide growth, will be partially compensated by the also existing hydrogen stemming from the dissociation of the water molecules. Given equal oxidation conditions, the oxide layer of Zry-4W is about 5-8 \% thicker than a layer of $\mathrm{ZrNb}$.

\subsection{Relative permittivity}

The capacity of the samples with silver electrodes was measured after annealing to $180{ }^{\circ} \mathrm{C}$, and the relative permittivity was computed using the known geometric factors. Measurements with $\mathrm{Au}$ electrodes gave comparable results, shown in Table 2. The value of 20.5 of the layer grown in steam on $\mathrm{Zr} 1 \mathrm{Nb}$ is near to the normally accepted bulk value, while the value for $\mathrm{Zry}-4 \mathrm{~W}$ is slightly lower. However, the relative permittivity is $27 \%$ and $34 \%$ lower in the oxides formed in air of $\mathrm{Zr} 1 \mathrm{Nb}$ and of Zry-4W, respectively.

\subsection{Time dependence of the electric current}

When a voltage is applied, a relatively large injection current $I_{\text {in }}$ flows. This gradually decreases with time, building up a space charge $Q$, until an equilibrium state defined by the ohmic resistance is finally reached. If the voltage is switched off, and the sample is short-circuited, there flows an adequate extraction current $I_{\mathrm{ex}}=-I_{\text {in }}$ of opposite polarity [13] of the form

$$
I_{\mathrm{ex}}=B \cdot t^{-n}
$$


The time integral of the extraction current gives the extracted charge

$$
Q e x=\int_{t_{1}}^{t_{2}} B^{-n} \mathrm{~d} t=B \frac{t_{2}^{1-n}-t_{1}^{1-n}}{1-n},
$$

equalling the injected charge, $Q_{\text {in }}=-Q_{\text {ex }}$. Due to the high resistance the injected charge remains practically unchanged and, as long as the layer is left open-circuited, it will only be discharged after a long time. The injected charge is a linear function of the injection voltage and of the injection time. The specific charge $Q / U$ has the dimension of a capacitance

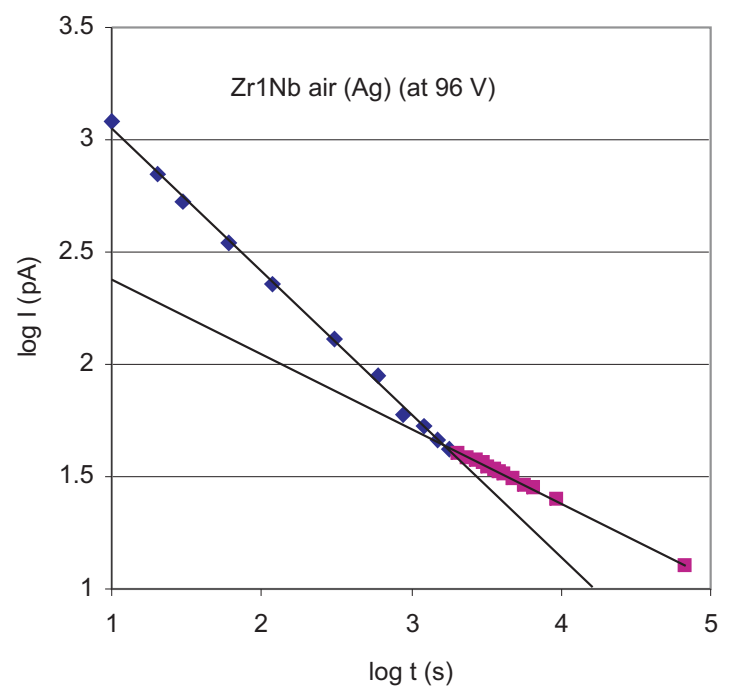

Fig. 1: Typical example of the time-dependent current drop after application of voltage. After $20 \mathrm{~min}$. no constant current level is reached, but the current continues to decreases with a smaller slope

and can be expressed as the charge density per unit voltage, being of the order of $\mu \mathrm{F} / \mathrm{cm}^{3}$. A typical example of the time dependence of the injection current is shown in Fig.1.

It can be seen that the current, $1 \mathrm{~s}$ after voltage application, is two orders of magnitude higher than half an hour later, when the injection phase is coming to an end, and constant current is expected to be established, as the current now begins to decrease. Contrary to expectation, however, there is only a bend in the straight line and the current continues to decrease with a lesser slope and even after 20 hours there is no end of the current drop. Similar behaviour of the other samples is presented in Table 3 . This influence of the elec-

Table 3: Comparison of injection currents of the various samples trode metal was not expected. The Ti substrate of the Au seems to act as potential barrier and gives rise to extremely long time delays. Therefore the results achieved using the Ag contacts were preferred, and were given greater weight. Thus the time for reaching the end of the injection current is from 15 to $20 \mathrm{~min}$. for all samples with Ag electrodes, which seems reasonable, whereas with $\mathrm{Au}$ electrodes there are extreme differences. There is a marked decrease in the specific capacitance going from $\mathrm{Zr} 1 \mathrm{Nb}$ steam to Zry-4W air, which is in accordance with the trend of decreasing conductivity.

\subsection{Short-circuit current and open-circuit voltage}

Measurement of the short-circuit current $I_{0}$ and the open-circuit voltage $U_{0}$ as functions of slowly rising temperature showed the current to increase exponentially, while the open-circuit voltage grew linearly, starting over $100{ }^{\circ} \mathrm{C}$. The open-circuit voltage $U_{0}$ can be measured directly by compensating of the short-circuit current with an opposing voltage of the same value but of opposite polarity. As this is rather time consuming, it is better to assess the voltage $U_{0}$ by computing the intersection point of a straight line, having the slope of the resistivity and put through the point of the short-circuit current, with the $x$-axis,

$$
U_{0}=I_{0} \frac{\rho w}{A} .
$$

The short-circit current of $\mathrm{Zr} 1 \mathrm{Nb}$ reached $2500 \mathrm{pA}$ at $210^{\circ} \mathrm{C}$ with an open-circuit voltage of $300 \mathrm{mV}$, the rate being $3 \mathrm{mV} /{ }^{\circ} \mathrm{C}$. Both samples of $\mathrm{Zry}-4 \mathrm{~W}$, oxidized in steam and in air, due to higher resistivity, achieved only a current of $5 \mathrm{pA}$ at $240{ }^{\circ} \mathrm{C}$ with an open-circuit voltage of only $5 \mathrm{mV}$. The flowing diffusion current, in accordance with Eq.(6), develops $U_{0}$ as the voltage drop across the resistance of the oxide layer.

\subsection{I-V characteristics}

The $I-V$ characteristics were measured at constant temperatures, from room temperature up to $220^{\circ} \mathrm{C}$ in steps of about $20^{\circ} \mathrm{C}$, and with voltages up to $90 \mathrm{~V}$, mostly in steps of $10 \mathrm{~V}$. The normally existing asymmetry of the complete $I-V$ characteristics due to a certain rectifying effect could be neglected in this case. Therefore only the forward voltage branch, with the positive terminal of the voltage source connected to the $\mathrm{Zr}$ metal of the sample, was measured.

The $I-V$ characteristics of the sample $\mathrm{Zr} 1 \mathrm{Nb}$ oxidized in steam, shown in Fig. 2, are normal space-charge limited cur-

\begin{tabular}{|c|c|c|c|c|c|c|c|c|}
\hline \multirow{3}{*}{$\begin{array}{l}\text { Sample } \\
\text { Oxidation } \\
\text { Electrode }\end{array}$} & \multicolumn{4}{|c|}{$\mathrm{Zr} 1 \mathrm{Nb}$} & \multicolumn{4}{|c|}{ Zry-4W } \\
\hline & \multicolumn{2}{|c|}{ steam } & \multicolumn{2}{|c|}{ air } & \multicolumn{2}{|c|}{ steam } & \multicolumn{2}{|c|}{ air } \\
\hline & $\mathrm{Au}$ & $\mathrm{Ag}$ & $\mathrm{Au}$ & $\mathrm{Ag}$ & $\mathrm{Au}$ & $\mathrm{Ag}$ & $\mathrm{Au}$ & $\mathrm{Ag}$ \\
\hline Exponent $(n)$ of injection & - & 0.35 & 0.76 & 0.7 & - & 0.56 & 0.76 & 0.47 \\
\hline Bend after $t$ (min.) & - & 15 & 115 & 20 & $17 \mathrm{~h}$ & 15 & 105 & 17 \\
\hline Exponent (n) of continuing drop & - & - & 0.26 & 0.35 & - & 0.16 & - & 0.14 \\
\hline Capacitance $\left(\mu \mathrm{F} / \mathrm{cm}^{3}\right)$ & 2.6 & 3.9 & 1.56 & 1.9 & 0.3 & 0.98 & 0.15 & 0.96 \\
\hline
\end{tabular}
rent curves following Eq.(1). At room temperature the resis- 


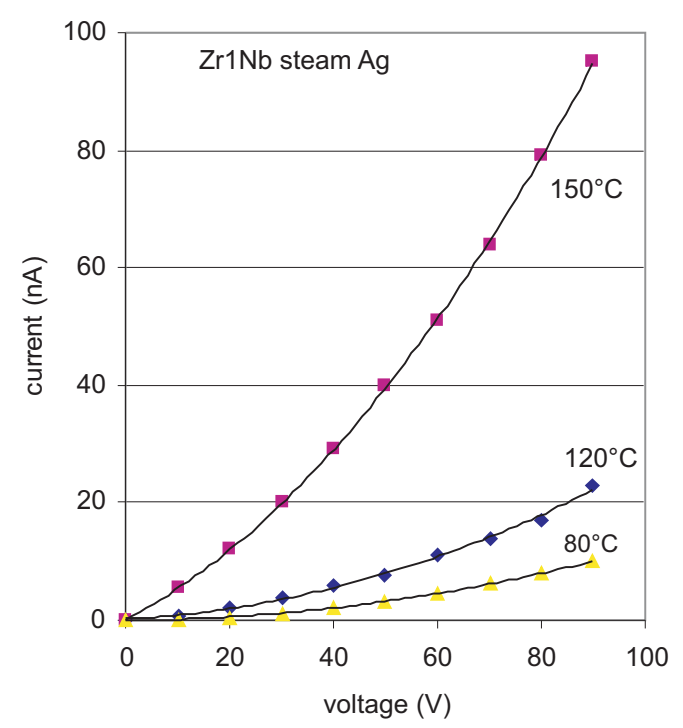

Fig. 2: Normal I-V characteristics of $\mathrm{Zr} 1 \mathrm{Nb}$ steam, with space-charge limited currents, observing Eq.(1)

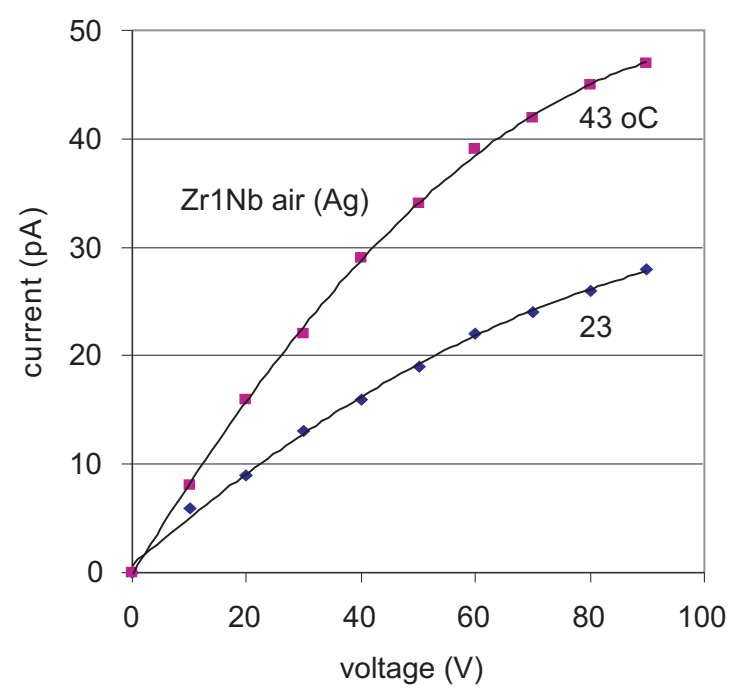

Fig. 3: Abnormal (sub-linear) $I-V$ characteristics of $\mathrm{Zr} 1 \mathrm{Nb}$ air at lower temperatures

tivity is $1.7 \times 10^{14} \Omega \mathrm{cm}$, with a mobility of $1.8 \times 10^{-9} \mathrm{~cm}^{2} / \mathrm{Vs}$ and a carrier concentration of $2 \times 10^{13} \mathrm{~cm}^{-3}$.

The specimen of $\mathrm{Zr} 1 \mathrm{Nb}$ grown in air at $500{ }^{\circ} \mathrm{C}$ was quite different. The $I-V$ characteristics at low temperatures were sublinear (Fig. 3), increasing less with growing voltages, but at higher temperatures gradually straightening and finally, after attaining a straight line $\left(\right.$ at $\left.90^{\circ} \mathrm{C}\right)$, they developed normal forms of space-charge limited current characteristics (Fig. 4). It is interesting to note that the fitted curves still follow Eq.(1),

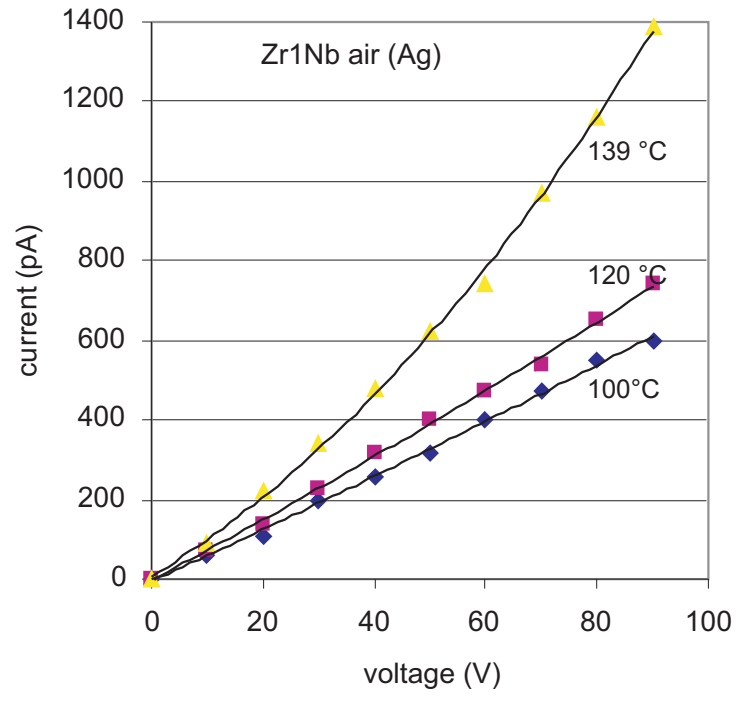

Fig. 4: Normal, space-charge limited current characteristics of the sample in Fig. 3, at higher temperatures

but with changing sign of coefficient $a$, indicating the curvature of the characteristics. The temperature dependence of coefficients $a$ and $b$ are given in Table 4 . The temperature dependent resistivity can be computed using coefficient $b$ in Eq.(2).

A similar behaviour was found in the Zry- $4 \mathrm{~W}$ samples. The sample oxidized in steam, like ZrlNb steam, was very near to a normal form of characteristics, only with an extraordinarily

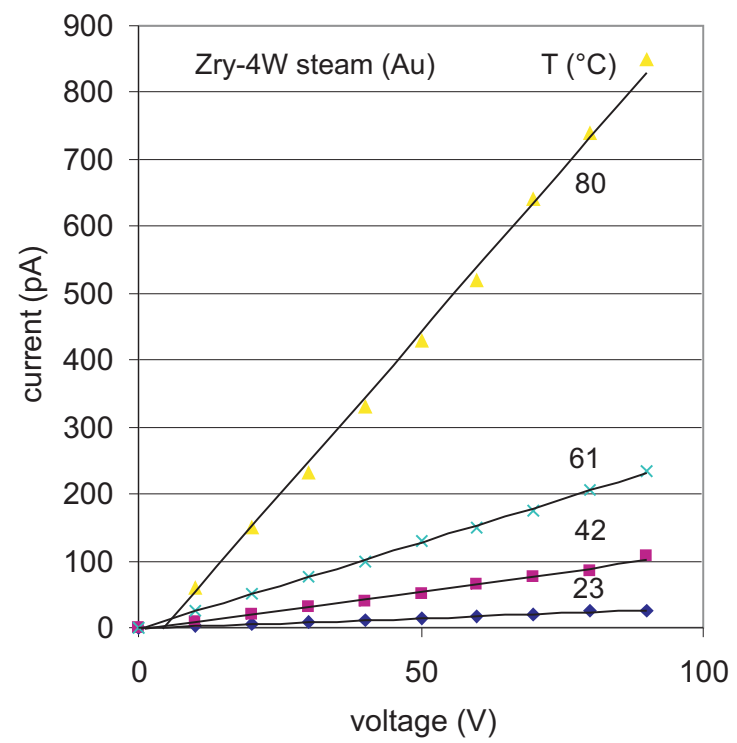

Fig. 5: I-V characteristics, linear up to $90 \mathrm{~V}$ and $220{ }^{\circ} \mathrm{C}$ of Zry- $4 \mathrm{~W}$ steam, without space-charge limited currents, although charges had been injected

Table 4: Temperature dependence of the coefficients of the polynomial (eq.(1) in $\mathrm{Zr} 1 \mathrm{Nb}$ air

\begin{tabular}{|l|c|c|c|c|c|c|c|}
\hline $\mathrm{T}\left({ }^{\circ} \mathrm{C}\right)$ & 23.5 & 43 & 62 & 82 & 100 & 120 & 139 \\
\hline$a\left(\mathrm{pA} / \mathrm{V}^{2}\right)$ & -0.0017 & -0.004 & -0.0045 & -0.0055 & +0.0045 & +0.0083 & +0.076 \\
\hline$b(\mathrm{pA} / \mathrm{V})$ & 0.458 & 0.884 & 1.977 & 5.246 & 6.433 & 7.444 & 8.354 \\
\hline
\end{tabular}




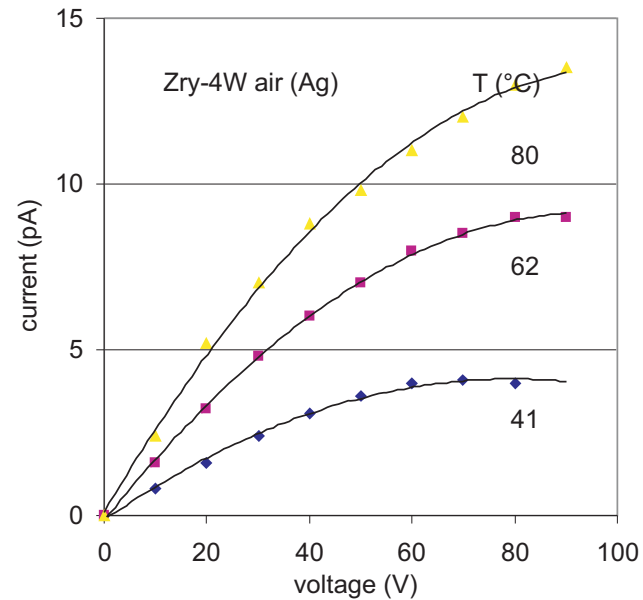

Fig. 6: Abnormal (sub-linear) I-V characteristics of Zry-4W air, similar to those in Fig. 3

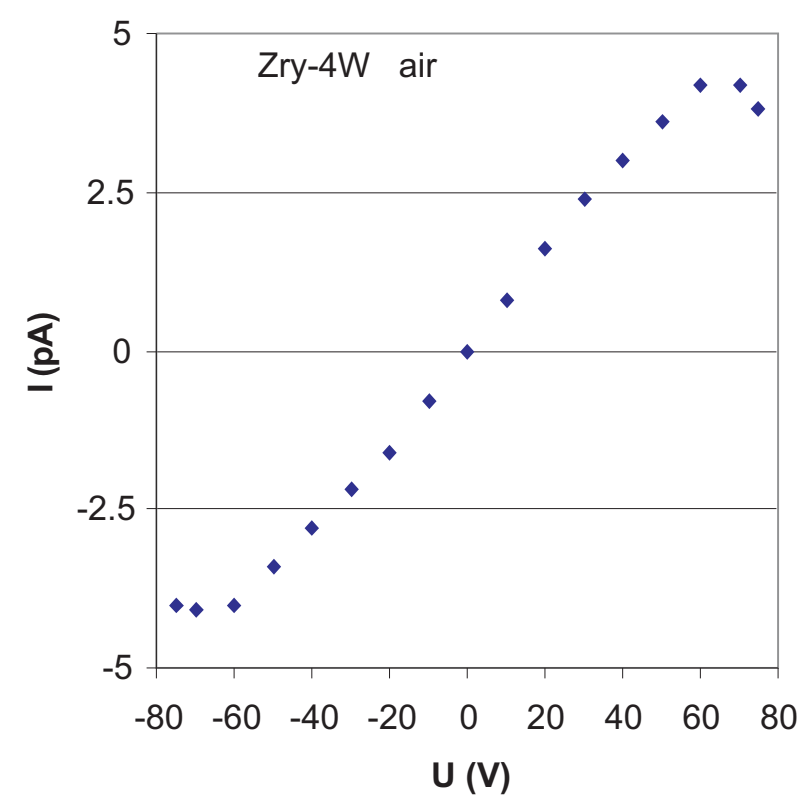

Fig. 7: Complete I-V characteristic of Zry-4W air, room temperature

long linear part, and the sample oxidized in air was sub-linear, like its counterpart of $\mathrm{Zr} 1 \mathrm{Nb}$ air. The $I-V$ characteristics of Zry-4W air, shown in Fig. 5, were linear up to $90 \mathrm{~V}$ and $220^{\circ} \mathrm{C}$, but space-charge limited currents were not observed, although injected and extracted charges of usual magnitude were measured, see Table 3 . The sub-linear characteristics of Zry-4W air are presented in Fig. 6, and the complete characteristics at room temperature in Fig. 7 show the symmetry of the positive and negative parts, together with the dropping currents at larger voltages. Similar complete characteristics of the other samples were measured, showing the symmetrical form without rectifying effects, and justifying the limitation to measurement of the positive branch only.

\subsection{Activation energy}

We used the results of current measurements at different temperatures and at low voltages near the origin, where only the linear (ohmic) part of the characteristicswere used to com-

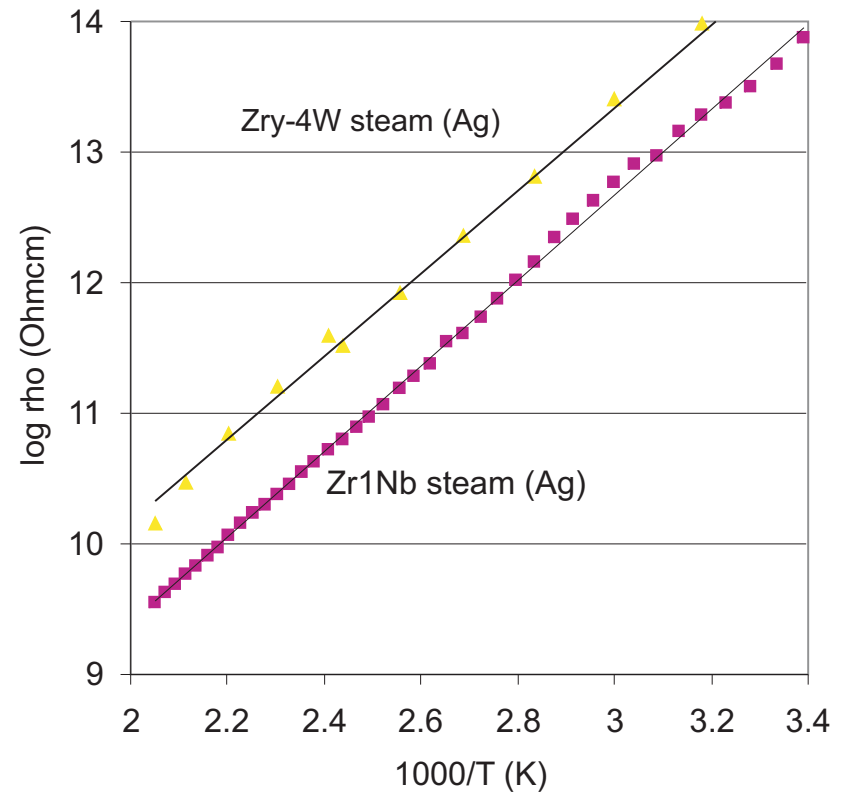

Fig. 8: Comparison of the temperature dependence of the resistivity of samples $\mathrm{Zr} 1 \mathrm{Nb}$ and of $\mathrm{Zry}-4 \mathrm{~W}$, both oxidized in steam at $425^{\circ} \mathrm{C}$, activation energy 1.30 and $1.27 \mathrm{eV}$, respectively

pute and plot the temperature dependence of the resistivity in the usual form of $\log \rho=f(1 / T)$ to assess the activation energy of the carriers from the slope of the straight line parts. The parallel straight lines from room temperature up to $220^{\circ} \mathrm{C}$ for the samples oxidized in steam, as shown in Fig. 8, indicate the existence of a single phase of the same kind, which also follows from the same grey colour of the oxides. Although the resistivity of Zry- $4 \mathrm{~W}$ is about one order of magnitude higher, the activation energies have the same value of $1.3 \mathrm{eV}$.

The complete $I-V$ characteristics of $\mathrm{Zr} 1 \mathrm{Nb}$ air for both $\mathrm{Ag}$ and $\mathrm{Au}$ electrodes at room temperature in Fig. 9 are slightly

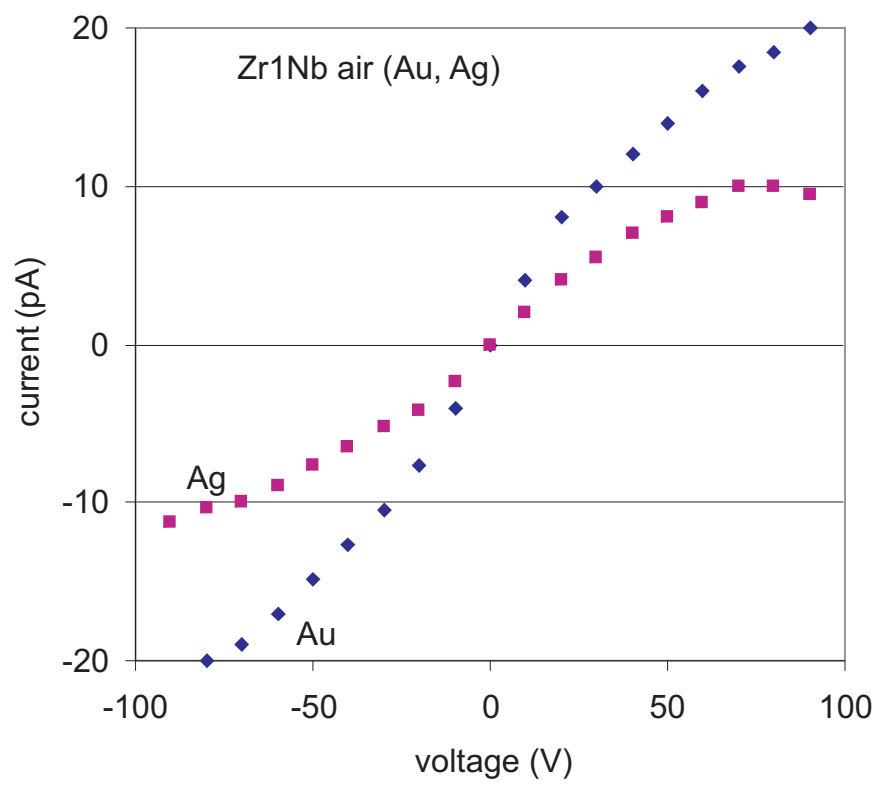

Fig. 9: Complete sub-linear $I-V$ characteristics typical for samples oxidized in air, but with slightly higher currents of the gold electrodes 


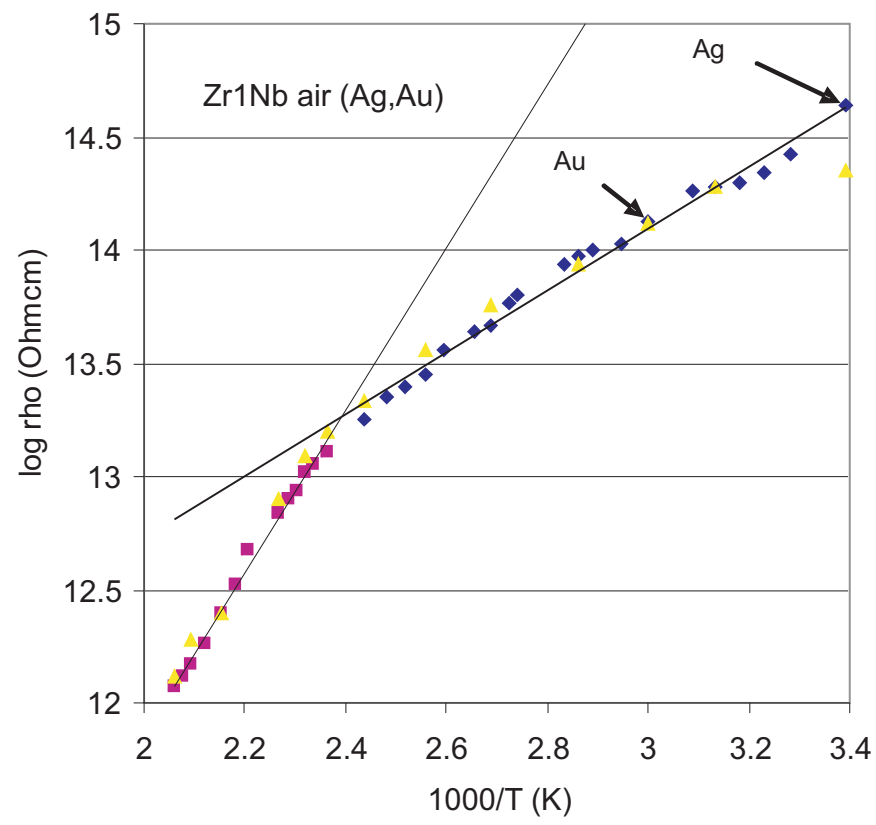

Fig. 10: Temperature dependence of $\mathrm{Zr} 1 \mathrm{Nb}$ air, no difference between $\mathrm{Ag}$ and Au contacts

different, but the temperature dependent resistivity in Fig. 10 is practically the same for both contact metals. The low activation energy of $0.5 \mathrm{eV}$, observed between room temperature and $140{ }^{\circ} \mathrm{C}$, increases to $1.3 \mathrm{eV}$ at higher temperatures. This is the same value as found in the samples oxidized in steam, and can be understood as the influence of the grey phase near the metal-oxide interface, whereas near the surface the white phase with $0.5 \mathrm{eV}$ prevails at lower temperatures.

A similar behaviour was found in the Zry-4W air sample with regard to the running of the temperature dependent resistivity, but with different values, obtained with the Au and Ag contacts. Fig. 11 shows the temperature dependence of the resistivity of Zry-4W air with both electrodes. The resistivity, using the Au electrode, was computed from current measurement at constant $10 \mathrm{~V}$ with continually rising temperature. At temperatures up to $160{ }^{\circ} \mathrm{C}$, the influence of the white phase prevails with low activation energy of about $0.3 \mathrm{eV}$, and at higher temperatures the grey modification dominates with $1.3 \mathrm{eV}$, on an average. Measurements at the same conditions on the Ag electrode gave at temperatures up to $140{ }^{\circ} \mathrm{C}$ gave a straight line with the same slope, only higher by a factor of 1.7. At higher temperatures the grey part of the layer was

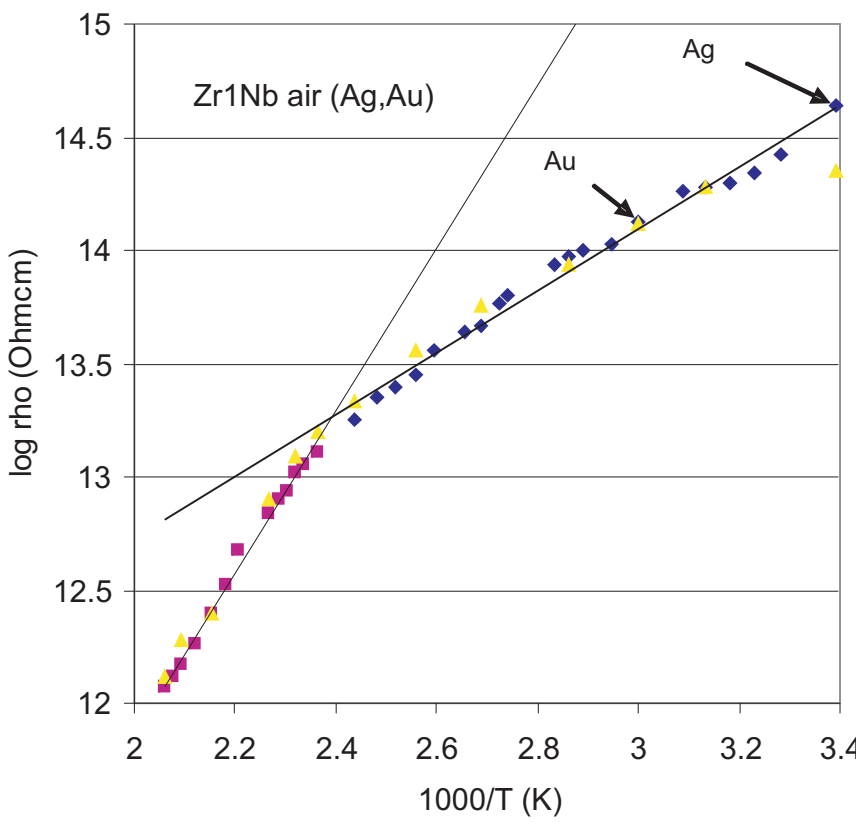

Fig. 11: Temperature dependence of Zry-4W air, with Au and Ag electrodes

activated with a higher activation energy, which appeared to be slightly different for the $\mathrm{Au}$ and $\mathrm{Ag}$ contacts, with a mean value of $1.3 \mathrm{eV}$. In this sample, unlike $\mathrm{Zr} 1 \mathrm{Nb}$ air, there was a marked influence of the electrode metals. Although the activation energies were found to be nearly the same, the temperature for changing over from 0.3 to $1.3 \mathrm{eV}$ was higher for the $\mathrm{Au}$ contact than for the $\mathrm{Ag}$ contact, $160^{\circ} \mathrm{C}$ and $140{ }^{\circ} \mathrm{C}$, respectively. A comparison of the activation energies is given in Table 5. The grey phase, independent of material and oxidation conditions, has an activation energy of $1.3 \pm 0.1 \mathrm{eV}$, whereas the white phase part, grown in air at $500{ }^{\circ} \mathrm{C}$, has a lower value of $0.4 \pm 0.1 \mathrm{eV}$.

The oxide films are not homogeneous, but consist of a substoichiometric black oxide layer of high conductivity, near the metal-oxide interface, as stated by Cox et al. [14], and of an almost stoichiometric white layer of high resistivity. At larger film thickness the high resistivity layer dominates. Fully oxidized layers are of monoclinic structure, whereas substoichiometric black layers with oxygen deficiency can have a tetragonal structure [15]. Moreover, part of the layer near the surface can be porous [14], so that painted-on electrode material could enter into the pores and alter the

Table 5: Comparison of the activation energies of the various samples

\begin{tabular}{|c|c|c|c|c|c|c|c|c|c|}
\hline \multicolumn{2}{|l|}{ Sample } & \multicolumn{4}{|c|}{$\mathrm{Zr} 1 \mathrm{Nb}$} & \multicolumn{4}{|c|}{ Zry-4W } \\
\hline Oxidation & colour & \multicolumn{2}{|c|}{ steam } & \multicolumn{2}{|c|}{ air } & \multicolumn{2}{|c|}{ steam } & \multicolumn{2}{|c|}{ air } \\
\hline Electrode & & $\mathrm{Au}$ & $\mathrm{Ag}$ & $\mathrm{Au}$ & $\mathrm{Ag}$ & $\mathrm{Au}$ & $\mathrm{Ag}$ & $\mathrm{Au}$ & $\mathrm{Ag}$ \\
\hline Energy $(\mathrm{eV})$ & grey & 1.3 & 1.3 & & & 1.21 & 1.25 & & \\
\hline up to $140^{\circ} \mathrm{C}$ & white & & & 0.45 & 0.54 & & & 0.30 & 0.30 \\
\hline over $160^{\circ} \mathrm{C}$ & grey & & & 1.34 & 1.43 & & & 1.43 & 1.15 \\
\hline Average (eV) & grey & $1.3 \pm 0.1$ & & & & & & & \\
\hline & white & $0.4 \pm 0.1$ & & & & & & & \\
\hline
\end{tabular}


effective thickness of the layers. The relative permittivity computed from capacitance measurements of specimens of different electrode metals often deviated from the accepted value of $\varepsilon_{r}=22$ for bulk zirconium oxide. This may be due to partly to the porosity of the layers or to wetting difficulties of the contacts, or to inhomogeneities of the layers [14]. Oxidation in aqueous surroundings leads to the development of hydrogen and can enter into the layers and even into the bulk zirconium [16].

\section{Conclusions}

The main results can be stated as follows:

(a) In steam at $425^{\circ} \mathrm{C}$ a substoichiometric grey oxide phase of high conductivity was formed with an activation energy of about $1.3 \mathrm{eV}$.

(b) In air at $500{ }^{\circ} \mathrm{C}$ the oxide was inhomogeneous, and at the surface there prevailed an almost stoichiometric white/ish phase with high resistivity and a lower activation energy of about $0.4 \mathrm{eV}$. Near the metal-oxide interface the grey phase with its activation energy of about $1.3 \mathrm{eV}$ became active at measuring temperatures over $140{ }^{\circ} \mathrm{C}$.

(c) The injection current, flowing when voltage was applied, decreased with time obeying a power law with $t^{-n}$, where the exponent was $n>0.5$, but did not attain constant equilibrium values. There was a bend at the expected time for equilibrium and the current continued to decrease at a lower slope with $n<0.5$.

(d) The inhomogeneous oxide grown in air formed a kind of junction between the grey and white phases, manifesting itself by sublinear $I-V$ characteristics, which even attained decreasing currents at rising voltages. The measuring points could still be fitted to the second order polynomial $I=a U^{2}+b U+c$, but with negative coefficient $a$. At higher temperatures the sublinear characteristics flattened out and became super-linear, indicating space-charge limited currents, when the influence of the grey phase with its higher activation energy was dominant.

(e) In Zry-4W samples there was a certain difference between $\mathrm{Au}$ and Ag contacts: currents were larger with Au contacts, but there was no difference in samples of $\mathrm{Zr} 1 \mathrm{Nb}$.

(f) The resistivity was about one order of magnitude greater in oxides formed in air.

(g) The relative permittivity was greater in oxides grown in steam and greater in $\mathrm{Zr} 1 \mathrm{Nb}$.

\section{Acknowledgments}

The support given to this work by UJP, Praha a.s. and by the Grant MSM 6840770015 grant is highly appreciated. Special thanks are due to Mrs. V. Vrtilkova for providing specimens of measured thickness.

\section{References}

[1] Frank, H.: J. Nucl. Mater. Vol. 340 (2005), p. 119.

[2] Frank, H.: J. Nucl. Mater. Vol. 360 (2007), p. 282.

[3] Franklin, D. G., Lang, P. M., Eucken, C. M., Garde A. M. (Eds.): Proc. $9^{\text {th }}$ Int. Symp. Nucl. Industry, ASTM, Philadelphia, 1991, p. 3, ASTM STP 1132.

[4] Corrosion of Zirconium Alloys in Nuclear Power Plants, IAEA-TECDOC-684, Vienna, 1993.

[5] Lee, S. J., Cho, E. A., Ahn, S. J., Kwon, H. S.: Electrochim. Acta, Vol. 46 (2001) p. 2605.

[6] Cox, B.: J. Nucl. Mater. Vol. 37 (1970), p. 177.

[7] Howlader, M.M.R., Shiiyama, H., Kinoshita, C., Kutsuwada, M., Inagaki, M.: J. Nucl.Mater. Vol. 253 (1998), p. 149.

[8] Inagaki, M., Kanno, M., Maki, H.: ASTM STP 1132 (1992), p. 437.

[9] Charlesby, A.: Acta Metall. Vol. 1 (1953), p. 348.

[10] Hartman, T. E., Blair, J. C., Bauer, R.: J. Appl. Phys. Vol. 37 (1966), p. 2468.

[11] Mott, N. F., Guerney, R. W.: Electronic Processes in Ionic Crystals, Clarendon, Oxford, 1940.

[12] Gould, R. D.: J. Appl. Phys. Vol. 53 (1982), p. 3353.

[13] Frank, H.: J. Nucl. Mater. Vol. 306 (2002), p. 85.

[14] Cox, B., Wong, Y.-M., Mostaghimi, J.: J. Nucl. Mater. Vol. 226 (1995), p. 272.

[15] Koski, K., Holes, J., Juliet, P.: Surf. Coat. Technol. Vol. 1207\&121 (1999), p. 303.

[16] Oskarson, M., Ahlberg, E. Sodervall, U., Anderson, U., Petterson, K.: J. Nucl. Mater. Vol. 289 (2001), p. 315.

Prof. RNDr. Helmar Frank, DrSc.

phone:+420224358559, +420221912407

e-mail: frank@km1.fjfi.cvut.cz

Department of Solid State Engineering

Czech Technical University

Faculty of Nuclear Sciences and Physical Engineering

Trojanova 13

12000 Prague 2, Czech Republic 